\title{
Hydroxyapatite particle characteristics influence the enhancement of the mechanical and chemical properties of conventional restorative glass ionomer cement
}

\author{
Kenji ARITA¹, Aimi YAMAMOTO¹, Yukari SHINONAGA¹, Keiko HARADA¹, Yoko ABE¹, Keizo NAKAGAWA',3,4 \\ and Shigeru SUGIYAMA $2,3,4$
}

\author{
${ }^{1}$ Department of Pediatric Dentistry, Institute of Health Biosciences, The University of Tokushima Graduate School, 3-18-15 Kuramoto, Tokushima \\ 770-8504, Japan \\ ${ }^{2}$ Department of Advanced Materials, Institute of Technology and Science, The University of Tokushima, 2-1 Minamijosanjima, Tokushima 770-8506, \\ Japan \\ ${ }^{3}$ Department of Geosphere Environment and Energy, Center for Frontier Research of Engineering, The University of Tokushima, 2-1 Minamijosanjima, \\ Tokushima 770-8506, Japan \\ ${ }^{4}$ Department of Chemical Science and Technology, Faculty of Engineering, The University of Tokushima, 2-1 Minamijosanjima, Tokushima 770-8506, \\ Japan \\ Corresponding author, Kenji ARITA; E-mail: kenji@dent.tokushima-u.ac.jp
}

\begin{abstract}
The aims of this study were to improve the mechanical and chemical properties of conventional restorative glass ionomer cement (GIC) by adding hydroxyapatite (HAp) preparations with different characteristics, and to investigate the underlying reaction mechanisms. Fuji IX GP ${ }^{\circledR}$ was used as the control GIC. The experimental GICs consisted of four HAp-particles with different characteristics added at 8 mass\% to Fuji IX-powder. All cements were prepared by mixing with Fuji IX-liquid (P/L=3.6). Four HApparticles were analyzed, and then the mechanical strengths and the fluoride-ion- release-recharge-behaviors of five GIC groups were evaluated. The results of this study demonstrate that the addition of HAp particles with highly reactive properties such as high specific surface area can enhance the flexural strength and fluoride ion release properties of conventional restorative GIC. Our results further indicate that HAp functions as an adsorbent and an ion exchangeable agent, resulting in improved mechanical and chemical properties of GIC.
\end{abstract}

Keywords: Glass ionomer, Hydroxyapatite, Particle characteristics, Mechanical properties, Fluoride release

\section{INTRODUCTION}

Glass ionomer cement (GIC) (also known as glass polyalkenoate cement) was invented by Wilson and Kent in $1971^{1)}$. GIC is widely used as a dental material, due to its ease of use, low coefficient of thermal expansion, good biocompatibility with bone pulp tissue, and long-term bonding to tooth surfaces and metals ${ }^{2-4}$. In addition, its unique fluoride ion release characteristics have anticaries, antimicrobial, and remineralization effects ${ }^{5}$. In 2000, the FDI World Dental Federation introduced a new preventive dental treatment concept, known as minimum intervention (MI), that promotes minimal tooth cavity preparation ${ }^{6}$. GIC is the most suitable dental material for $\mathrm{MI}^{7}$. Moreover, the World Health Organization (WHO) launched atraumatic restorative treatment (ART), developed in the mid-1980s as a public health program and first implemented, in Africa, by Frencken ${ }^{8}$. ART, which relies on GIC's natural bonding to tooth and its release of fluoride to prevent dental caries, involves the excavation of softened dentin followed by the direct filling of the cavity with GIC. This procedure does not require complicated techniques, dental chairs, rotary instruments, or light curing machines; thus, it is an ideal restorative treatment for use in developing countries. However, research in Syria showed that the cumulative survival rate of ART restorations after 6.3 years is $66.1 \%^{9)}$, so the strength and endurance of GIC requires improvement.

The poor mechanical properties of GIC, and its sensitivity to desiccation and moisture ${ }^{10)}$, have prompted research into overcoming these shortcomings ${ }^{11}$. For example, the incorporation of amalgam, silver, and metal powders as reinforcements into GIC powder have been reported, but these products have inferior aesthetic appearance and decreased bonding strength to enamel ${ }^{12}$. Light-cured GIC has also been investigated, where resin and a light-curing catalyst are added to hasten the setting and to improve the mechanical strength of $\mathrm{GIC}^{13)}$. Although light-cured GIC is widely used, resin-reinforced GIC has remarkably high flexural strength ${ }^{13)}$ but lower compressive strength than conventional GIC $^{14)}$. Moreover, resin-modified GIC can irritate dental pulp, has biological side-effects, and causes cytotoxicity and secondary caries; these negative characteristics are not found in conventional GIC $^{15,16)}$. Mechanical strength could be improved by incorporating $\mathrm{SiC}$ whiskers or short fibers into GIC ${ }^{17,18)}$, but this approach may not be possible because of the fear that these very small fibers could travel to and lodge into vital organs, thus posing a health threat similar to that posed by asbestos fibers.

Hydroxyapatite [HAp: $\mathrm{Ca}_{10}\left(\mathrm{PO}_{4}\right)_{6} \mathrm{OH}_{2}$ ] has excellent biocompatiblity, and its composition and crystal structure are similar to the apatite in human dental 
structures and bone tissue. In 1984, Yamamoto ${ }^{19)}$ added HAp to conventional GIC to improve the biocompatibility of GIC. Yap et al. ${ }^{20)}$ later reported that the addition of HAp increased the hardness of GIC and recommended the use of this bioactive cement in orthopedics. Arita ${ }^{21)}$ reported improved mechanical strength of GIC, in the absence of resins or fillers, by the addition of HAp whiskers. The addition of HAp granules also strengthened GIC, not by reinforcement but through chemical interactions with the cement matrix ${ }^{22)}$. However, there has been no report to notice the powder characteristic of HAp in the improving properties of GIC by using HAp.

The primary aim of this study was to evaluate the effectiveness of four HAp particles with different sizes and properties on the mechanical and chemical properties of conventional restorative GIC. We also analyzed the particle characteristics of GIC powder and the four HAp particles, and compared the physical and chemical properties of GIC/HAp mixtures.

\section{MATERIALS AND METHODS}

\section{Materials}

Conventional posterior glass ionomer restorative cement, Fuji IX GP ${ }^{\circledR}$ (Fuji IX, lot nos. 0602021, 0602031, 0701201, GC Corp., Tokyo, Japan) was used as the control GIC group (control-GIC). Fuji IX-powder is mainly composed of fluoro-alumino-silicate glass containing $\mathrm{Si}, \mathrm{Al}$ and $\mathrm{Na}$, and $\mathrm{Sr}$ instead of $\mathrm{Ca}$. Fuji IX-liquid is composed of polyacrylic acid, polybasic carboxylic acid, and distilled water.

Four HAp-particles were used: HAp200 (Taihei Chemical Industrial Co., Ltd., Osaka, Japan), NanoHAp (SANGI Co., Ltd., Tokyo, Japan), HAp100 (Taihei Chemical Industrial Co., Ltd., Osaka, Japan), and HAp100f, which was made by grinding HAp100 to less than $20 \mu \mathrm{m}$ using an automatic ball mill (Vibration Micro-Pulveriser P-0, Fritsch Japan Co., Ltd., Kanagawa, Japan) in our laboratory. Based on the results of the preliminary experiments, 8 mass percent of the Fuji IX-powder was replaced with individual HAp samples and mixed in $50 \mathrm{~mL}$ tubes using a tube mixer (Eddy Mixer S-10, Koike Precision Instruments Co., Ltd, Tokyo, Japan).

In experimental GIC groups, HAp200-, NanoHAp-, HAp100- and HAp100f-added GICs were named A200-, NanoA-, A100- and A100f-GIC, respectively.

Morphology, particle size distribution, microcompressive strength, and specific surface area measurements of Fuji $I X$-powder and the four HAp-particles

The morphologies, particle size distributions, and microcompressive strengths of Fuji IX-powder and four HAp-particles were analyzed using a scanning electron microscope (SEM; JSM5300, JEOL Co., Tokyo, Japan), a laser diffraction particle size analyzer (SALAD-3100 and 2200, Shimadzu, Kyoto, Japan), and a microcompressive testing machine (MCT-W500, Shimadzu, Kyoto, Japan), respectively. The mean microcompressive strength was calculated using $C=2.8 P / \pi d^{223)}$, where $P$ is the maximum load $(\mathrm{N})$ and $d$ is the diameter $(\mathrm{mm})$ of the particle $(n=6)$.

The specific surface areas of four HAp-particles were measured by a Brunauer-Emmet-Teller (BET) nitrogen gas adsorption method $^{24)}$ using an automated surface area and porosimetry analyzer (TriStar 3000, Micromeritics Instrument Co., Norcross, GA). The BET specific surface area of each sample was calculated from the adsorption and desorption isotherms of nitrogen for each HAp sample.

$X$-ray diffraction (XRD), transmission electron microscopy (TEM), and selected area electron diffraction (SAED) studies of the four HAp-particles

The crystallite sizes of HAp200, NanoHAp, and HAp100 were analyzed by XRD, TEM, and SAED. HAp100f was excluded since it is the same as HAp100 except for particle size and surface properties. XRD patterns were recorded with a vertically mounted diffractometer system (RINT 2500 VHF, Rigaku, Tokyo, Japan) using $\mathrm{CuK} \alpha$ radiation. The scanning range $(2 \theta)$ was from $1^{\circ}$ to $70^{\circ}$ at a scan speed of $2 \% \mathrm{~min}$ and a step size of $0.02^{\circ}$ in continuous mode. The crystallite size of the HAp samples was determined by the Scherrer equation $(1)^{25)}$

$D=0.9 \lambda / \beta \cos \theta$

where $D$ is the crystallite size, $\lambda$ is the wavelength of the incident X-ray $(0.15418 \mathrm{~nm}), \theta$ is the diffraction angle of the (211) peak, and $\beta$ is the half-width of the peak. TEM images of the samples were recorded with the HITACHI H-800 ELECTRON MICRO SCOPE (Hitachi HighTechnologies Co., Tokyo, Japan) using an accelerating voltage of $200 \mathrm{kV}$. The TEM samples were finely ground in an agate mortar and dispersed into ethanol by ultrasonication. The crystallite structures of the samples were analyzed by SAED of the TEM images.

Flexural strength test of conventional and HApsAll cements (control-, A200-, NanoA-, A100-, and A100f-GICs) were prepared by mixing with Fuji IX-liquid using a plastic spatula on a mixing pad at the recommended powder/liquid ratio (P/L) of 3.6. Samples ( $n=6)$ measuring $3 \mathrm{~mm} \times 3 \mathrm{~mm} \times 25 \mathrm{~mm}$ were prepared for each group. Samples were clamped for $10 \mathrm{~min}$ at room temperature, unclamped and kept for $50 \mathrm{~min}$ at $100 \%$ humidity at $37^{\circ} \mathrm{C}$, then submerged in distilled water and stored for 23 hours at $37^{\circ} \mathrm{C}$. The samples were then subjected to a three-point bending test in a universal testing machine (Autograph AG10TA, Shimadzu, Kyoto, Japan) at a crosshead speed of $0.5 \mathrm{~mm} / \mathrm{min}$. For each sample group, representative fracture surfaces from the three-point bending test were dried, gold-coated, and observed by SEM (JSM5300, JEOL, Tokyo, Japan).

Compressive strength test of conventional and HApsaugmented GICs

All compressive strength test samples were mixed at a $\mathrm{P} / \mathrm{L}$ of 3.6 as described for the flexural strength test. Samples $(n=6)$ measuring $6 \mathrm{~mm}$ in diameter and $12 \mathrm{~mm}$ 
in height were prepared for the control-, A200-, NanoA-, A100- and A100f -GICs following the procedures outlined in ISO9917-1:2007. After 24 hours of storage, the samples were tested using a universal testing machine (Autograph DSS-500, Shimadzu, Kyoto, Japan) at a crosshead speed of $1.0 \mathrm{~mm} / \mathrm{min}$.

Measurement of fluoride ion release and recharge behaviors of conventional and HAps-augmented GICs

All samples for this experiment were mixed at a P/L of 3.6. Six discs ( $10 \mathrm{~mm}$ diameter $\times 2 \mathrm{~mm}$ thick) for each GIC group were made using a polyethylene mold for fluoride ion release and recharge measurements. Samples were covered with celluloid strips and pressed with a glass plate under a $500 \mathrm{~g}$ load. After $10 \mathrm{~min}$, samples were removed from the mold and stored at $37^{\circ} \mathrm{C}$ and $100 \%$ relative humidity for 50 minutes. Samples were individually suspended by a nylon thread in $10 \mathrm{~mL}$ distilled water in sealed containers and stored at $37^{\circ} \mathrm{C}$. The concentrations of fluoride released into the water were measured, and the distilled water was replaced every 24 hours for 30 days. For the measurements, each disk was removed from the water, dried on filter paper, and immediately immersed in $10 \mathrm{~mL}$ fresh distilled water for further equilibration. The fluoride concentrations in the water samples were measured at room temperature using a fluoride electrode (Model 9609BN, Orion Research, Boston, MA) connected to an expandable ion analyzer (Model 720A, Orion Research). Buffer solution (1 mL, TISAB III, Thermo Fisher Scientific, Beverly, MA) was added to the water sample. After 14, 19, and 24 days, the disks were recharged in 10 $\mathrm{mL} \mathrm{NaF}$ solution (containing 9,000 ppm fluoride ion) for 5 minutes, rinsed with $5 \mathrm{~mL}$ running distilled water, quickly dried, and immediately immersed in $10 \mathrm{~mL}$ fresh distilled water. Fluoride ion release concentrations from these recharged samples were measured daily for 30 days.

SEM observation of the fracture surfaces and energy dispersion X-ray spectrometry (EDS) analysis of conventional and HAps-augmented GICs

For each GIC group, representative fracture surfaces from the flexural strength test were dried, gold-coated, and observed under an SEM (JSM5300, JEOL Co., Tokyo, Japan). Elemental analyses of the control- and A100-GICs were carried out for representative fracture surfaces using an EDS detector (IncaPentaFET $\times 3$, Oxford Instruments PLC., Oxford, UK) and an SEM (SU-70, Hitachi High-Technologies Co., Tokyo, Japan). The pressure voltmeter was set at $20 \mathrm{kV}$ for 300 seconds. The elemental compositions of the matrix parts of representative fractured surfaces of A100- and A100f-GICs were also determined with an EDS detector (Link Pentafet, Oxford Instruments PLC, Oxford, UK).

X-ray photoelectron spectroscopy (XPS) analysis of conventional and HAps-augmented GICs

The matrices of control-GIC and HAps-added GICs were analyzed quantitatively for chemical composition using an XPS (PHI5000, ULVAC-PHI Co., Kanagawa, Japan). Samples were prepared by syringe-loading the mixed cement $(\mathrm{P} / \mathrm{L}=3.6)$ into $6 \mathrm{~mm}$ diameter $\times 2 \mathrm{~mm}$ high stainless steel split molds, pressing with cellulose acetate sheets and a glass plate, and clamping for 1 hour to obtain matrix-rich surfaces according to Jones' methods ${ }^{26)}$. For XPS, the X-ray source was MgK $\alpha$, at 400 $\mathrm{W}$ and $14 \mathrm{kV}$. The mass of each element was computed by calculating the peak area for each element, which was then expressed as the XPS peak area ratio of each element to $\mathrm{C} 1 \mathrm{~s}$.

\section{Statistical analysis}

The mean and standard deviation (S.D.) was calculated for each group. Analysis was performed using Scheffé's post hoc F test.

\section{RESULTS}

SEM observation, particle size distribution, microcompressive strength, and specific surface area of Fuji IX-powder and four HAp-particles

An SEM image of Fuji IX-powder is shown in Fig. 1A-1. The particles were sharp-edged, polygonal, and ranged from 1 to $20 \mu \mathrm{m}$ in diameter, as shown in Fig. 1A-2. In the analysis of particle size distribution, the mean size of Fuji IX-powder was $5.3 \mu \mathrm{m}$, and $10.0 \%$ to $90.0 \%$ distribution was 1.5 to $18.9 \mu \mathrm{m}$, reflecting a wide range of distribution. The mean ( \pm S.D.) microcompressive strength of Fuji IX-powder was $182.8 \pm 26.6 \mathrm{MPa}$.

SEM images of the four HAp-particles are shown in Fig. 1B-1(a-d). HAp 200 (Fig. 1B-1a) comprised hexagonal crystals, which aggregated to form particles with a width of about $0.5 \mu \mathrm{m}$ and a length of $2-3 \mu \mathrm{m}$, but could condense to form aggregates about $10 \mu \mathrm{m}$ in size. The particle size of NanoHAp (Fig. 1B-1b) was about 10-20 $\mathrm{nm}$, but the crystals could clump together to form particles greater than $10 \mu \mathrm{m}$ in diameter. HAp100 (Fig. 1B-1c) comprised columnar crystals about $200-300 \mathrm{~nm}$ in diameter, but could condense to form aggregates about 200-300 $\mu \mathrm{m}$ in size. HAp100f particles (Fig. 1B-1d) were oblong-shaped and 10-20 $\mu \mathrm{m}$ in diameter, which were round with tiny adhered nano-sized HAp particles. The particle size distributions of the four HAps are shown in Fig. 1B-2. For NanoHAp, even following ultrasonication to separate the clumped particles, the average size was about $3.4 \mu \mathrm{m}$ in diameter, with most of the particles in the range of $1-10 \mu \mathrm{m}$. The mean diameters of HAp 100 f and HAp200 were 11.4 and $13.6 \mu \mathrm{m}$, respectively, and the mode diameter was $17.0 \mu \mathrm{m}$ for both, with a range of about 2-40 $\mu \mathrm{m}$. HAp100 had the highest mean particle diameter at $236.3 \mu \mathrm{m}$ with a range distribution (10.0\%-90.0\% distribution) of 94.5-422.0 $\mu \mathrm{m}$ (Fig. 1B-2).

The microcompressive strength values of three HAps are shown in Fig. 1B-3. The small particle size of NanoHAp made measurement of its microcompressive strength impossible using current analysis methods. The mean microcompressive strength of HAp100 and HAp100f $(0.76 \pm 0.04 \mathrm{MPa}$ and $0.98 \pm 0.11 \mathrm{MPa})$ was significantly lower than that of HAp200 (1.54 $\pm 0.23 \mathrm{MPa})$ 
A-1

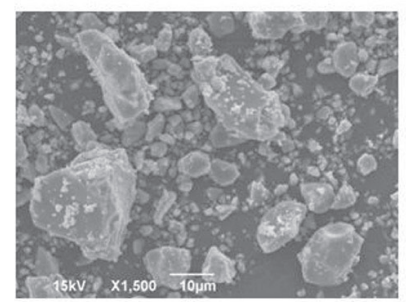

(a)
A-2

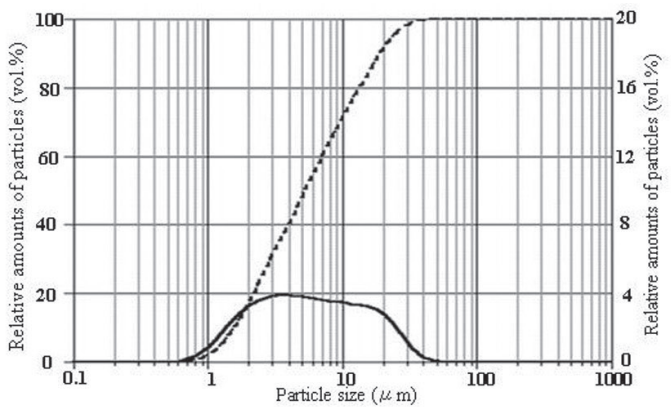

(b)

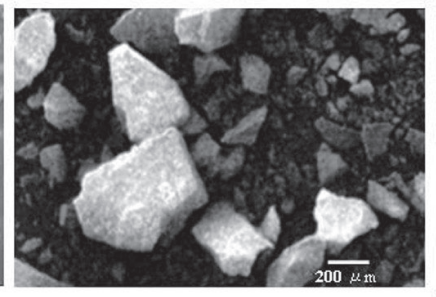

(d)

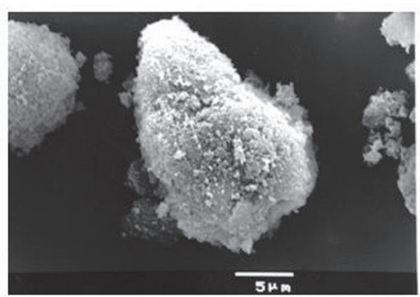

B-4

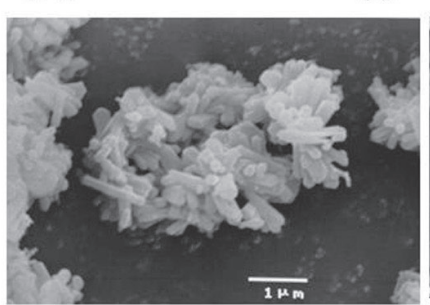

B-2

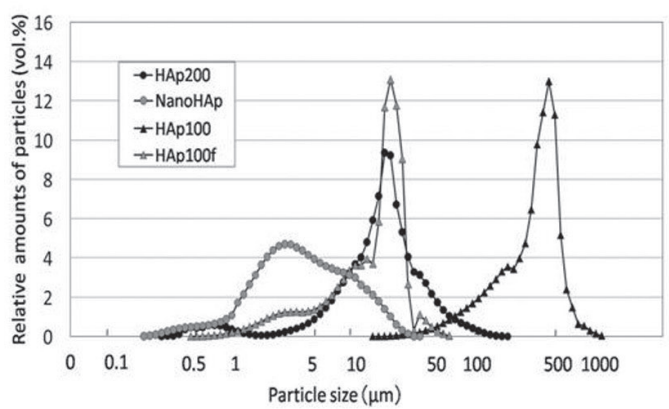

B-3

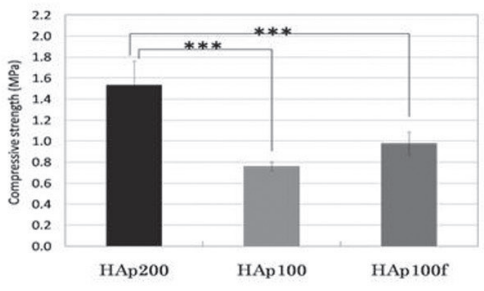

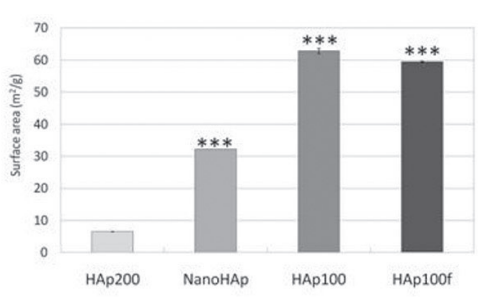

Fig. 1 Particle characteristics of Fuji IX powder and four HAp-particles.

A-1: SEM image of Fuji IX powder $(\times 1,500)$

A-2: Particle size distribution of Fuji IX powder

B-1: SEM image of four HAp-particles: (a) HAp200 (×20,000), (b) NanoHAp (×50,000), (c) HAp100 (×100) and (d) HAp100f $(\times 3,500)$

B-2: Particle size distributions of the four HAp-particles

B-3: Microcompressive strength of HAp200, HAp100, and HAp100f

B-4: Specific surface area of the four HAp-particles

$(p<0.001)$

The specific surface areas of the four HAp-particles are compared in Fig. 1B-4. The values of the mean surface area of the particles were: HAp100 (62.82 \pm 0.86 $\left.\mathrm{m}^{2} / \mathrm{g}\right)>$ HAp100f $\left(59.45 \pm 0.24 \mathrm{~m}^{2} / \mathrm{g}\right)>>$ NanoHAp $\left(32.21 \pm 0.01 \mathrm{~m}^{2} / \mathrm{g}\right)>$ HAp200 $\left(6.52 \pm 0.08 \mathrm{~m}^{2} / \mathrm{g}\right)$. There were significant differences among the groups $(p<0.001)$.

XRD, TEM, and SAED analyses of four HAp-particles The XRD patterns of HAp200, NanoHAp, and HAp100 (HAp100f) particles are shown in Fig. 2A. The patterns of all samples were in good agreement with the ASTM data (JCPDS: 721243) for hydroxyapatite. The XRD peaks of NanoHAp and HAp100 were broader than those of HAp200. Moreover, the crystallite sizes of NanoHAp and HAp100 were smaller than that of HAp200 (Table
1). TEM images and SAED patterns of HAp200, NanoHAp, and HAp100 are shown in Fig. 2B. The HAp200 sample contained rod-like sharp-edged particles about $40 \mathrm{~nm}$ in diameter and $400 \mathrm{~nm}$ in length (Fig. 2Ba). The NanoHAp sample consisted of agglomerated nano-particles of diverse shape (Fig. 2Bb). The HAp100 sample showed agglomerated rod-shaped particles, with a particle size of $20 \mathrm{~nm}$ in diameter and 30-120 nm in length. SAED of the HAp200 sample provided a clear diffraction pattern with discrete spots, indicating well-formed HAp crystals (Fig. 2Ba inset). The SAED patterns of NanoHAp and HAp100 are shown in Fig. 2Bb and c. The SAED patterns showed spotty ring patterns indicating random orientation in the crystalline phase of HAp; this is particularly pronounced in HAp100 (Fig. $2 \mathrm{Bc})$. 
A

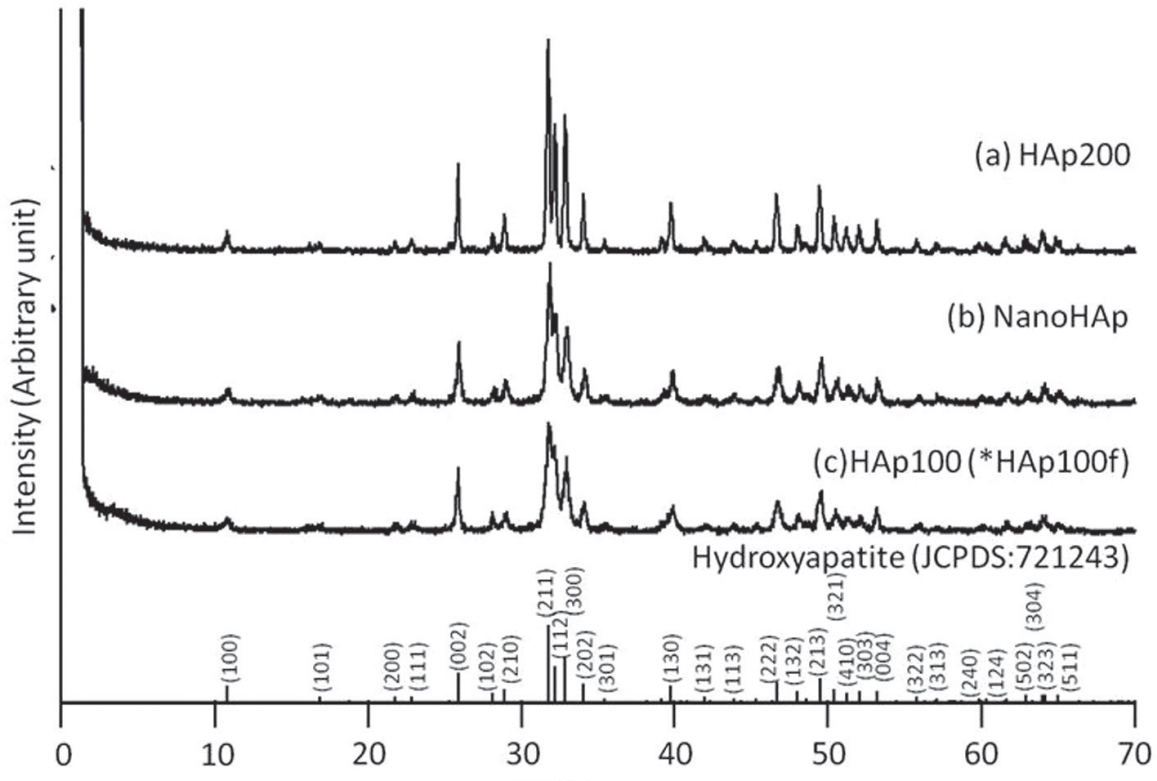

B

(a)

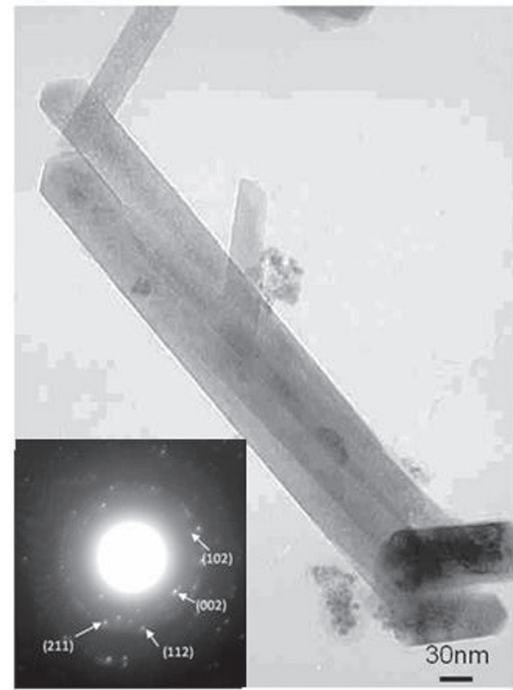

(b)

$2 \ominus /$ degree

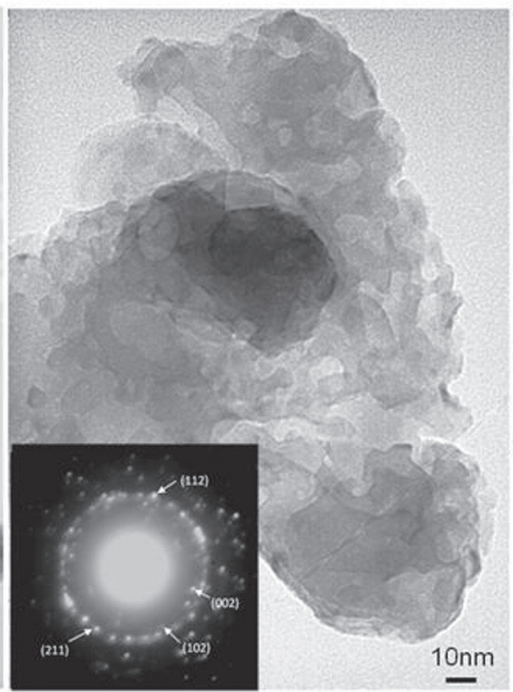

(c)

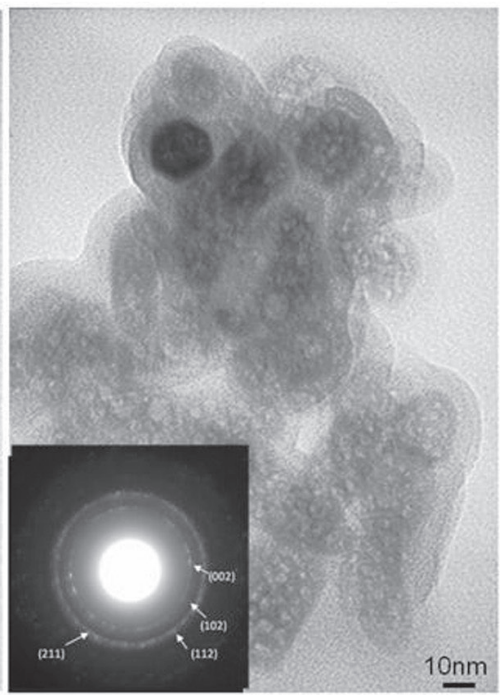

Fig. 2 XRD, TEM, and SAED analyses of HAp200, NanoHAp, and HAp100 particles.

A: XRD patterns of (a) HAp200, (b) NanoHAp, and (c) HAp100

B: TEM image showing typical morphology of (a) HAp200, (b) NanoHAp, and (c) HAp100, and SAED patterns (inset)

Table 1 Crystallite sizes of HAp-particles calculated from the XRD (211) peak

\begin{tabular}{lc}
\hline Sample & Crystallite size (nm) \\
\hline HAp200 & 41.3 \\
NanoHAp & 23.4 \\
HAp100 (*HAp100f) & 21.8 \\
\hline
\end{tabular}

* HAp100f is the same crystal as HAp100, since HAp100f is finely ground HAp100.
Flexural strength and compressive strength of conventional and HAps-augmented GICs

The results of the flexural strength test conducted 24 hours after mixing the control-GIC and four HAps-added GICs are shown in Fig. 3A. The flexural strength values of A100f- and NanoA-GICs were significantly higher than that of the control GIC.

The results of the compressive strength test 24 hours after mixing the control-GIC and four HAps-added GICs are shown in Fig. 3B. There was no significant

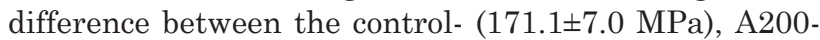
(176.4 $\pm 18.6 \mathrm{MPa}) \mathrm{GICs}$, and the control- and A100f- 
A

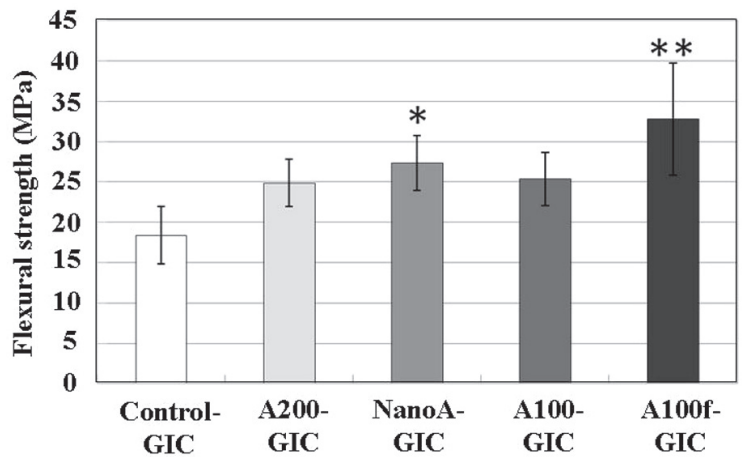

B

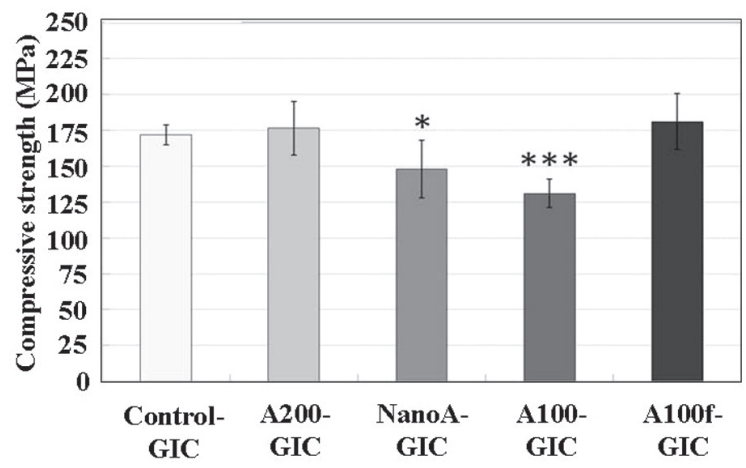

Fig. 3 Mechanical properties.

A: Flexural strength of the control-GIC and the four HAps-added GICs after 24 hours from mixing

B: Compressive strength of the control-GIC and the four HAps-added GICs after 24 hours from mixing

Significant difference between the control-GIC and HAps-added GICs ${ }^{*} p<0.05,{ }^{* *} p<0.01$, and $* * * p<0.001)$

(181.0 $\pm 19.4 \mathrm{MPa})$ GICs.

The A100- (131.0 $\pm 10.0 \mathrm{MPa})$ and NanoA- $(148.0 \pm 20.0$ $\mathrm{MPa}$ GICs showed significantly lower compressive strength than the control-GIC $(p<0.001$ and $p<0.05)$.

Fluoride ion release and recharge behavior of conventional and HAps-augmented GICs

The mean fluoride ion release values are shown in Table 2. In addition, accumulated fluoride ion release values are shown in Fig. 4. Over a 30-day period, which included three recharges, the HAps-added GICs except the NanoA-GIC exhibited higher fluoride ion release and recharge doses than the control-GIC. In particular, the A100f-GIC showed significantly higher daily fluoride ion release than the other GICs $(p<0.001)$ (Table 2).

SEM observation of fractured surfaces and EDS analysis of conventional and HAps-augmented GICs

SEM images of fractured surfaces of the control-, A200and A100f-GICs are shown in Fig. $5 \mathrm{~A}(\mathrm{a}-\mathrm{c})$. The control-GIC exhibited an irregular fracture surface. A200- and A100f-GICs exhibited a somewhat smoother fracture surface with fewer box-shaped glass-particle debonded holes (i.e., holes formed following release of glass particles from the GIC fracture surface) and many fractured glass particles. However, the HAp particles added in the A200- and A100f-GICs could not be observed by SEM.

SEM images (lower and higher magnification) of the fractured segment of HAp100 particle (prior to being added to cement) are shown in Fig. 5B-1a. The result of EDS point analysis in this region of the SEM image is shown in Fig. 5B-1b. SEM images (lower and higher magnification) of the fractured surface, and the result of EDS point analysis of this region in the A100-GIC are shown in Fig. 5B-2a and 5B-2b. The samples of the A100-GIC could only be found in HAp100 particles added into the cement on the fractured surface by SEM. In the high magnification SEM image of the original HAp100 particle, the particles have a rough surface with countless countless concavo-convex surfaces made by theconhesive nano-size HApcrystals (Fig. 5B-1a). However, in the fractured surface of A100-GIC, the SEM image of HAp100 particle shows a smooth surface made by the penetration of the GIC matrix into the HAp pores by the adsorption ability of HAp (Fig. 5B-2a). EDS point analysis of HAp100 incorporated into A100-GIC provided the distribution of $\mathrm{F}, \mathrm{Si}, \mathrm{Al}$, and $\mathrm{Sr}$ (originating from Fuji IX glass powder), in addition to $\mathrm{P}$ and $\mathrm{Ca}$ originating from HAp (Fig. 5B-1b and 5B-2b).

\section{EDS and XPS analysis of the cement matrix}

The elemental compositions of the matrix phases of the control-, A100- and A100f-GICs are shown in Table 3. The A100- and A100f-GICs included larger amounts of $\mathrm{Ca}$ and $\mathrm{P}$ in the matrix, whereas little Ca was present in the matrix of the control-GIC. EDS spectra of the matrix in the A100- and A100f-GICs are shown in Fig. 6A. The Ca peak is more clearly evident in the EDS spectrum of the A100f-GIC than the A100-GIC (Fig. 6A-b).

The XPS narrow-scan spectra for Ca2p in the matrices of the control-GIC and HAps-added GICs are shown in Fig. 6B-a. The Ca2p peak was not detected in the control-GIC matrix, but is evident in the matrix layers of the HAps-added GICs. The Ca2p/C1s peak area ratios of the control-, A200-, NanoA-, A100-, and A100f-GICs were $0.00,0.02,0.11,0.04$, and 0.07 , respectively. Calcium was detected in all HAps-added groups, with higher $\mathrm{Ca}$ in the NanoA- and A100f-GICs than in the A200- and A100-GICs. The XPS narrow-scan spectra for F1s in the matrices of the control-GIC and HAps-added GICs are shown in Fig. 6B-b. The F1s peak was clearly detected around $686.0 \mathrm{eV}$ in the control-GIC, but was present as indistinct peaks in HAps-added GICs' matrix. The $\mathrm{F} 1 \mathrm{~s} / \mathrm{C} 1 \mathrm{~s}$ peak area ratios of the control-, A200-, NanoA-, A100- and A100f-GICs were 0.16, 0.14, $0.16,0.30$, and 0.33 , respectively; the ratio is highest for the A100- and A100f-GICs.

\section{DISCUSSION}

The purpose of this study was to improve the mechanical 
Table 2 Fluoride ion release from the control and four HAps-added GICs over a 30-day period $\left(\mu \mathrm{g} / \mathrm{cm}^{2}\right)$

Significant difference between the control group and four HAps-added GICs $\left({ }^{*} p<0.05,{ }^{* *} p<0.01\right.$, and $* * * p<0.001$ )

Recharge: After 14, 19, and 24 days, the samples were recharged by exposure to 9,000 ppm $\mathrm{F}^{-}$ion for 5 min.

\begin{tabular}{l|c|c|c|c|c|c|c|c|c|c}
\hline Group Day & 1 & 2 & 3 & 4 & 5 & 6 & 7 & 8 & 9 & 10 \\
\hline Control-GIC & 41.3 & 9.4 & 6.0 & 5.3 & 5.1 & 4.3 & 4.1 & 3.5 & 5.1 & 3.0 \\
\hline A200-GIC & 69.5 & 18.4 & 10.3 & 6.2 & $7.2^{*}$ & 8.0 & 7.5 & 8.0 & 6.6 & 5.1 \\
\hline NanoA-GIC & 43.0 & 15.7 & 9.7 & 8.3 & 5.6 & 6.3 & 4.3 & 4.2 & 2.7 & 3.2 \\
\hline A100-GIC & 62.0 & 18.5 & 11.1 & 6.6 & 7.0 & 8.1 & 7.7 & 9.4 & 6.9 & 5.0 \\
\hline A100f-GIC & $82.8^{* *}$ & $27.3^{* *}$ & $15.7^{* * *}$ & 8.3 & $8.3^{* * *}$ & $11.7^{* *}$ & $10.5^{* *}$ & $12.4^{* *}$ & $9.9^{*}$ & $7.0^{* *}$ \\
\hline
\end{tabular}

\begin{tabular}{l|c|c|c|c|c|c|c|c|c|c}
\hline Group Day & 11 & 12 & 13 & 14 & 15 & 16 & 17 & 18 & 19 & 20 \\
\hline Control-GIC & 2.8 & 2.4 & 2.7 & 2.6 & 68.6 & 7.1 & 2.9 & 4.1 & 2.1 & 29.7 \\
\hline A200-GIC & 5.3 & 4.6 & 4.2 & 4.4 & $167.0^{*}$ & 16.9 & 5.2 & 6.4 & 4.0 & 60.2 \\
\hline NanoA-GIC & $4 . \mathrm{s} 6$ & 2.1 & 4.8 & 3.0 & 32.2 & 11.3 & 5.7 & 5.1 & 3.8 & 23.8 \\
\hline A100-GIC & 5.5 & 4.6 & 4.3 & 4.4 & 147.3 & 17.2 & 5.3 & 6.3 & 4.2 & 59.4 \\
\hline A100f-GIC & $7.8^{* *}$ & 5.0 & $5.8^{* *}$ & $5.8^{* *}$ & $168.6^{*}$ & $24.1^{*}$ & $6.5^{* *}$ & $8.1^{* *}$ & $5.3^{* *}$ & $65.3^{*}$ \\
\hline
\end{tabular}

\begin{tabular}{l|c|c|c|c|c|c|c|c|c|c}
\hline Group Day & 21 & 22 & 23 & 24 & 25 & 26 & 27 & 28 & 29 & 30 \\
\hline Control-GIC & 4.5 & 3.1 & 2.2 & 2.2 & 28.7 & 3.7 & 3.8 & 2.7 & 2.6 & 2.6 \\
\hline A200-GIC & 9.4 & 5.3 & 3.8 & 3.6 & 58.1 & 7.9 & 6.7 & 4.4 & 4.6 & 4.2 \\
\hline NanoA-GIC & 4.7 & 2.1 & 1.9 & 2.2 & 36.0 & 5.6 & 3.1 & 2.6 & 2.4 & 2.1 \\
\hline A100-GIC & 9.6 & 5.7 & 4.1 & 3.6 & 58.9 & 8.1 & 6.7 & 4.6 & 4.6 & 4.1 \\
\hline A100f-GIC & $11.9^{*}$ & $6.9^{* *}$ & $5.3^{* *}$ & $4.7^{* *}$ & $68.8^{*}$ & $10.9^{*}$ & $8.4^{* *}$ & $5.9^{* *}$ & $5.9^{* * *}$ & $5.4^{* * *}$ \\
\hline \multicolumn{9}{|r|}{}
\end{tabular}

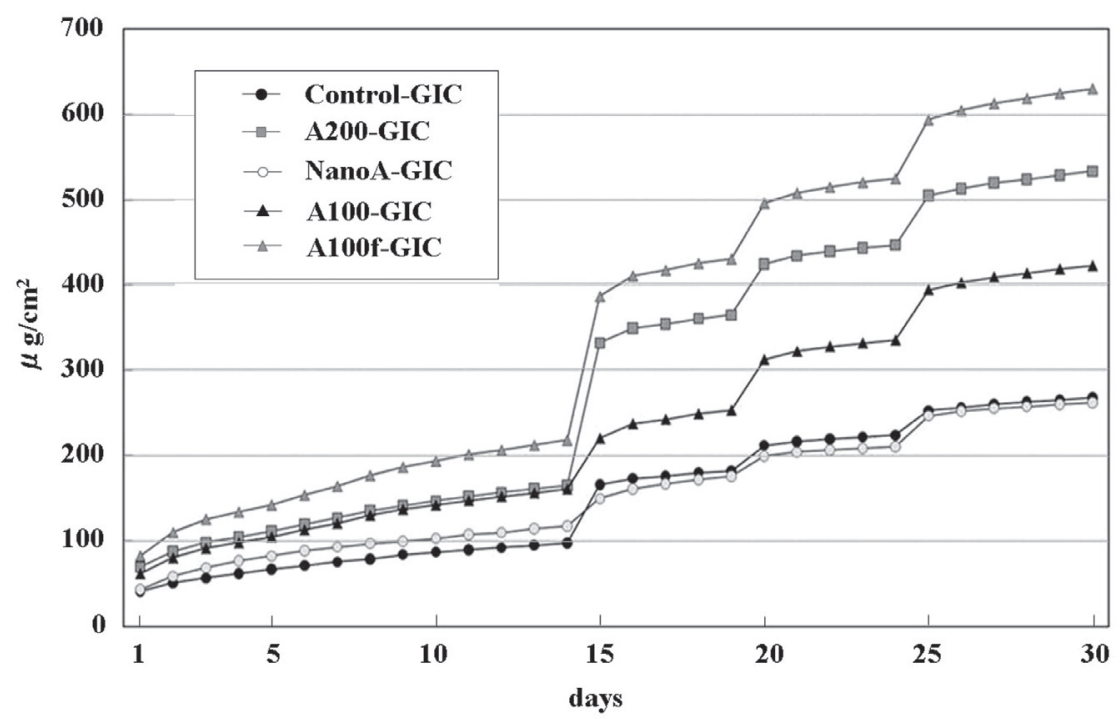

Fig. 4 Cumulated fluoride ion release and recharge for the control-GIC and HAps-added GICs over a 30-day period. 
A

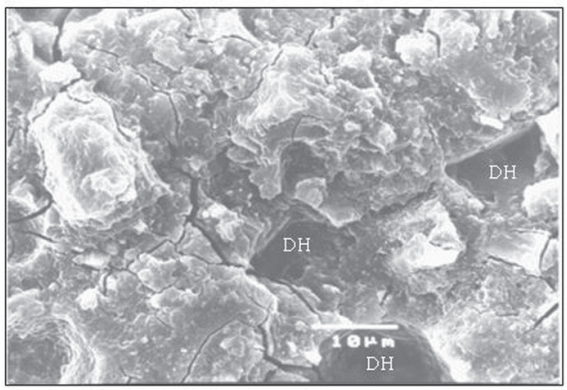

(a)

(a) (b)

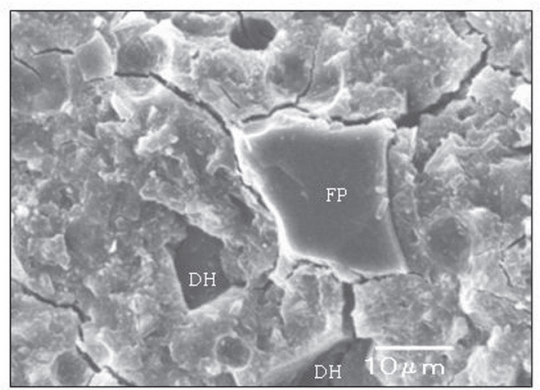

(c)

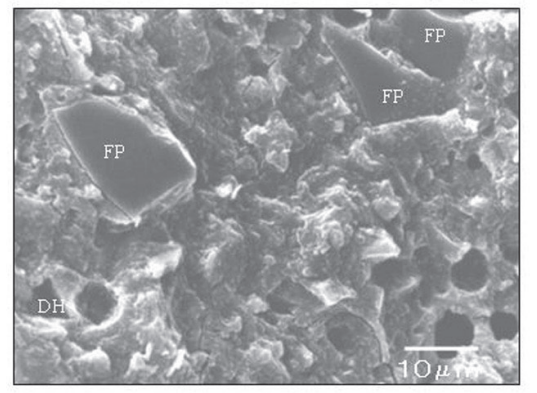

B-1
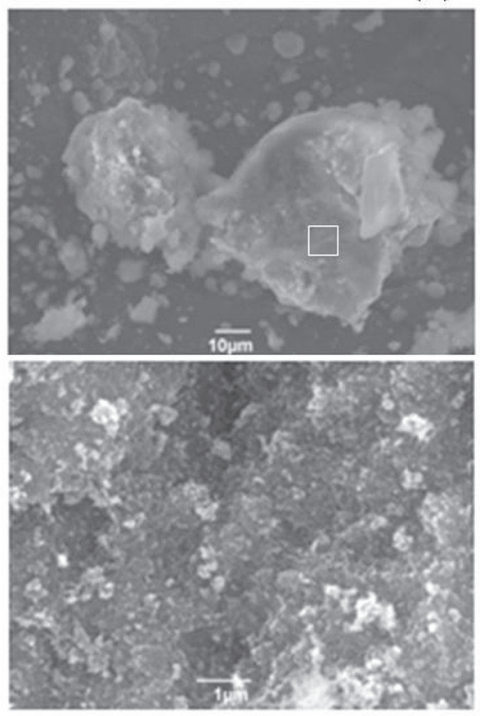

(b)

\begin{tabular}{|c|c|}
\hline & Atomic\% \\
\hline $\mathrm{CK}$ & 6.7 \\
\hline $\mathrm{OK}$ & 41.0 \\
\hline $\mathrm{FK}$ & 0.0 \\
\hline $\mathrm{AlK}$ & 0.0 \\
\hline $\mathrm{SiK}$ & 0.0 \\
\hline $\mathrm{PK}$ & 14.8 \\
\hline $\mathrm{CaK}$ & 37.5 \\
\hline $\mathrm{SrL}$ & 0.0 \\
\hline total & 100.0 \\
\hline
\end{tabular}

(a)

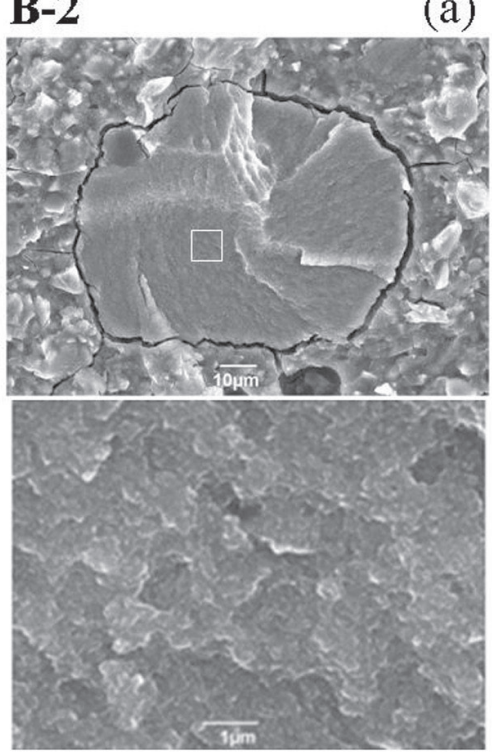

(b)

\begin{tabular}{|c|c|}
\hline & Atomic\% \\
\hline $\mathrm{CK}$ & 14.0 \\
\hline $\mathrm{OK}$ & 6.0 \\
\hline $\mathrm{FK}$ & 0.6 \\
\hline $\mathrm{AlK}$ & 16.5 \\
\hline $\mathrm{SiK}$ & 0.6 \\
\hline $\mathrm{PK}$ & 18.5 \\
\hline $\mathrm{CaK}$ & 37.6 \\
\hline $\mathrm{SrL}$ & 6.2 \\
\hline total & 100.0 \\
\hline
\end{tabular}

Fig. 5 SEM and EDS point analysis of representative fracture surfaces.

SEM images of representative fractured surfaces of (a) control-GIC $(\times 2,000)$, (b) A200-GIC $(\times 2,000)$ and (c) A100f-GIC $(\times 2,000)$. Fractured glass particles $(F P)$, glass-particle-debonded hole $(\mathrm{DH})$

B-1 (a) SEM images (upper: $\times 1,000$, lower: $\times 15,000$ ) and (b) EDS point analysis of a HAp100 particle

B-2 (a) SEM images (upper: $\times 1,000$, lower: $\times 15,000)$ and (b) EDS point analysis of HAp in the A100-GIC

Table 3 Comparison of the ratio of elements in the matrices of the control-, A100-, and A100f-GICs

\begin{tabular}{lcccccccc}
\hline Group & $\mathrm{Na}$ & $\mathrm{Al}$ & $\mathrm{Si}$ & $\mathrm{P}$ & $\mathrm{Ca}$ & $\mathrm{Ti}$ & $\mathrm{Sr}$ & $\mathrm{T}$ \\
\hline Control-GIC & $3.0 \pm 0.3$ & $33.9 \pm 0.4$ & $36.0 \pm 0.4$ & $8.5 \pm 0.3$ & $0.1 \pm 0.0$ & $1.0 \pm 0.1$ & $17.5 \pm 0.3$ & 100.0 \\
A100-GIC & $3.5 \pm 1.7$ & $32.8 \pm 0.3$ & $33.6 \pm 1.7$ & $9.9 \pm 0.3$ & $2.3 \pm 0.4$ & $1.0 \pm 0.1$ & $16.9 \pm 0.5$ & 100.0 \\
A100f-GIC & $2.6 \pm 0.1$ & $29.4 \pm 1.6$ & $30.8 \pm 1.8$ & $13.2 \pm 1.4$ & $8.5 \pm 2.6$ & $0.7 \pm 0.1$ & $14.8 \pm 0.6$ & 100.0 \\
\hline
\end{tabular}

and chemical properties of GIC using the chemical reaction behavior of HAp. The mechanism of adhesion of GIC to tooth structure is based on a substitution reaction between the carbonyl anion of polyacrylic acid in the liquid component of GIC, and the hydroxyl groups, Ca ions and phosphoric acid in the HAp which is the main component of tooth. This is followed by the formation of a macromolecular electrolyte-chain in $\mathrm{HAp}^{11,27)}$. On the basis of adsorption and infrared spectroscopic studies, Wilson et $a l .^{28)}$ postulated that, during adsorption, polyacrylate penetrates the surface of HAp, displacing and replacing surface phosphate. Calcium ions are displaced from HAp along with phosphate as part of a complex series of ionic exchanges. Wilson et al. inferred that, as a consequence of those interactions, an "intermediate layer" of calcium and aluminum phosphates and polyacrylates would form at the interface between the cement and HAp ${ }^{11,28,29)}$. This layer is very resistant to acid and is difficult to break ${ }^{28)}$. HAp is a well-known biocompatible functional material for use in 
A

(a)

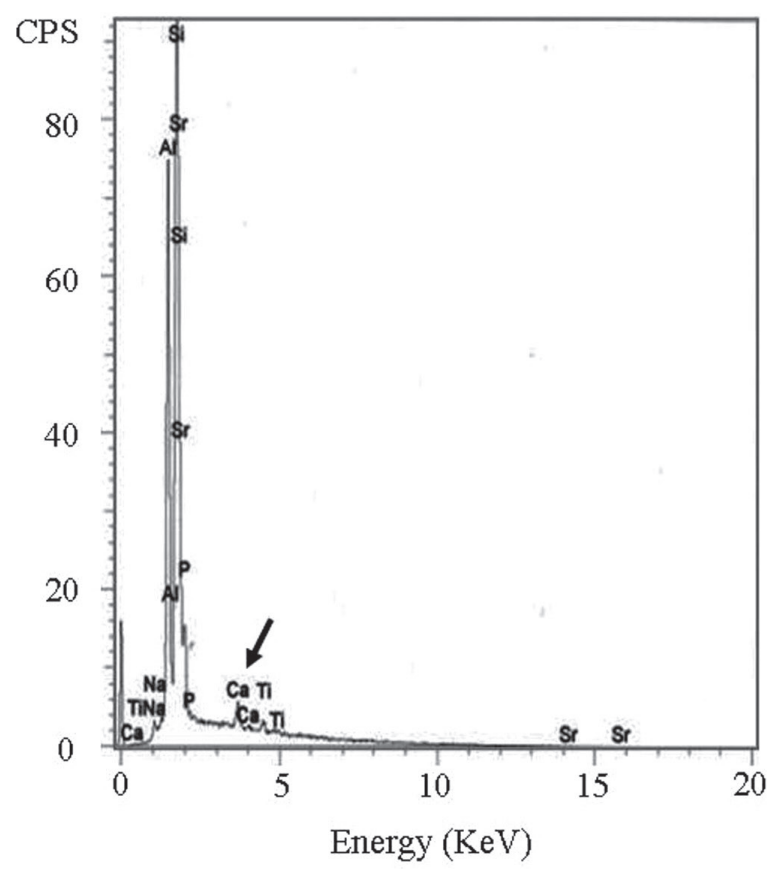

B

(a)

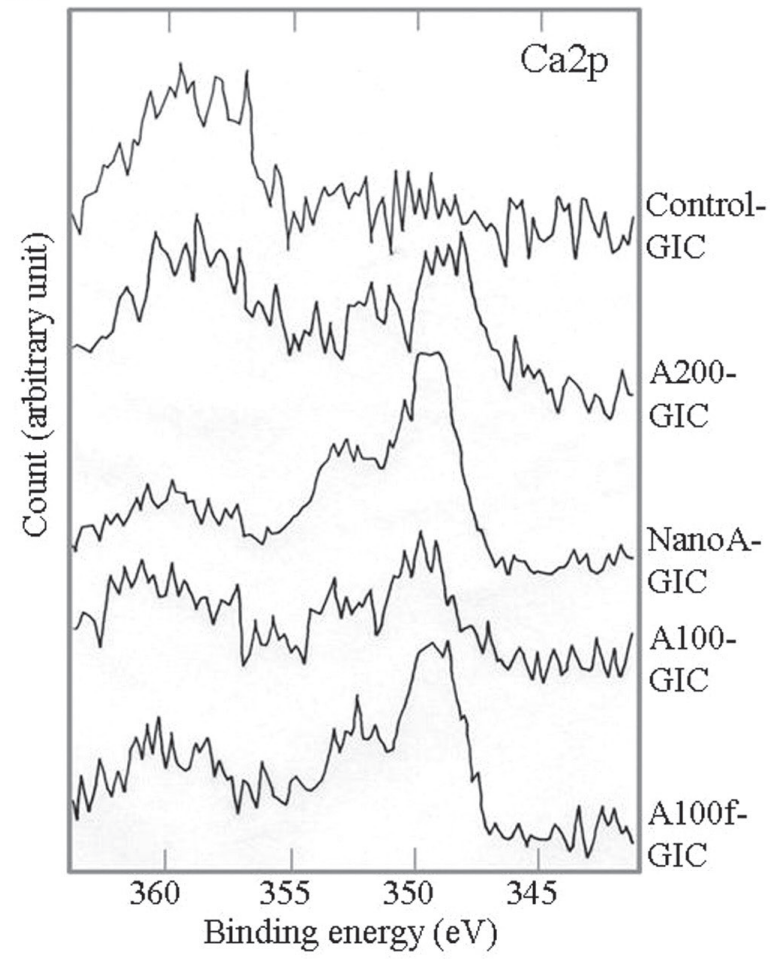

(b)

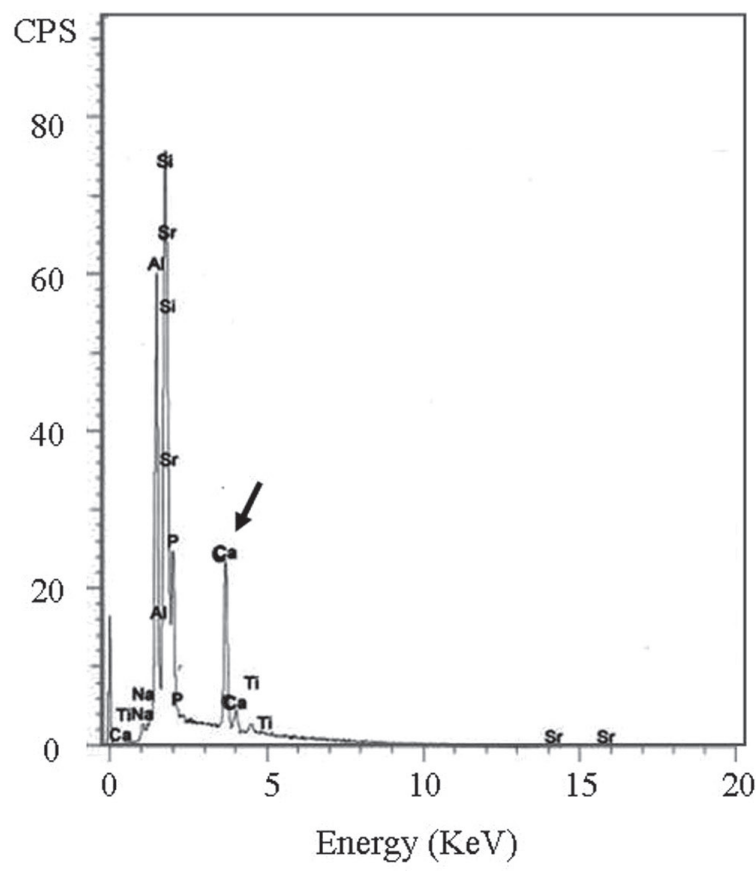

(b)

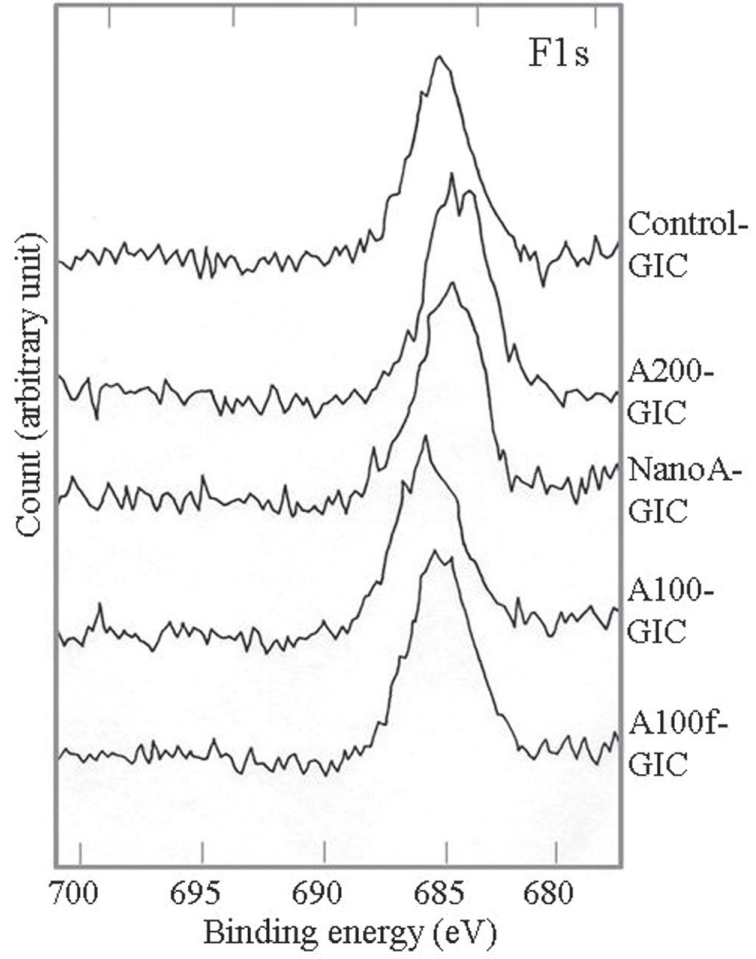

Fig. 6 EDS and XPS spectra of the matrix.

A: EDS spectra of the matrix of (a) A100- and (b) A100f-GICs. Black arrows indicate Ca peaks.

B: Narrow-scan spectra of XPS analysis for Ca2p (a) and F1s (b) in the matrix layers of the control-GIC and HAps-added GICs. 
ion exchange and adsorbent materials, and as a catalyst. Therefore, the incorporation of HAp into GIC may improve both the biocompatibility of GIC and enhance its mechanical properties.

We previously demonstrated that the strength of GIC is improved by addition of HAp200 particles ${ }^{30)}$. In the present study, HAp100f particles was generated from commercial HAp100 particles, which is composed of porous particles about $240 \mu \mathrm{m}$ in size, by mill grinding. Our intention was that the resulting mechano-chemical effects would produce better results than those obtained in our previous study. It has been reported that severe mechanical actions on solid surfaces lead to physical and chemical changes in the near-surface regions where the solids come into contact under mechanical forces ${ }^{31}$. These effects are generally termed "mechano-chemical effects". HAp100f particles were crushed to about $10 \mu \mathrm{m}$ in diameter. HAp200 was selected for comparison because its particle size is similar to that of HAp100f. The average diameter of NanoHAp, also chosen because of its extremely small particle size (about 1-20 $\mu \mathrm{m}$ ), was the smallest of the four HAps, at about $3 \mu \mathrm{m}$. Because the shape of HAp samples in this study had a great difference, it was not recognized the relation between their particle size and their specific surface area. Characterizations of the four HAp-particles showed that HAp100 and HAp100f have higher specific surface area and lower compressive strength than HAp200, and that the particle characteristics of NanoHAp were between HAp100 (HAp100f) and HAp200. In the specific surface area of HAps, it was predicted that $t$ HAp100f was smaller than that HAp100 theoretically. However, the result of this study showed the data of the latter was slightly higher than the former. We understood that the surface areas of HAp100f and HAp100 did not have a difference about those data. Furthermore, XRD, TEM, and SAED studies showed that HAp200 had the highest crystallinity, and HAp100 and HAp100f had lower crystallinity than NanoHAp. Thus, HAp100f has the highest reactivity of the four HAps studied in this investigation.

Fuji IX was selected as the base GIC material because it is one of the strongest commercially available conventional restorative GIC, and is recommended for this reason by WHO for ART. GIC glass is mainly composed of $\mathrm{SiO}_{2}, \mathrm{AlO}_{3}, \mathrm{CaF}_{2}, \mathrm{Na}_{3} \mathrm{AlF}_{6}$, and $\mathrm{AlPO}_{4}$. However, Sr can be substituted for Ca with little change in the GIC structure in order to increase the opacity of GIC to X-rays, because $\mathrm{Sr}$ and $\mathrm{Ca}$ have similar ionic radii $\left(\mathrm{Sr}^{2+}=1.13 \AA, \mathrm{Ca}^{2+}=0.99 \AA\right)^{11)}$. Fuji IX contains Sr instead of $\mathrm{Ca}^{32)}$. In this study, the presence of $\mathrm{Sr}$ and the absence of $\mathrm{Ca}$ in Fuji IX powders were verified by EDS and XPS analysis. It is therefore advantageous to use Fuji IX for investigating the contributions of $\mathrm{Ca}$ to the characteristics of HAp.

Sced and Wilson ${ }^{33)}$ and Irie ${ }^{12)}$ improved the flexural strength of GIC by adding amalgam and silver, respectively. However, they also reported decreased resistance to wear and compressive strength. Arita ${ }^{18)}$ reported that the incorporation of $\mathrm{SiC}$ whiskers into GIC improved transverse strength and fatigue resistance, but decreased compressive strength. Thus, the addition of reinforcements improves some properties of GIC and decreases others, especially compressive strength. Yamamoto $^{19)}$ and Nicholson ${ }^{34}$ reported that the compressive strength of HAp-containing GIC decreased as the mass of HAp increased. In this study, all HAps-added GICs showed higher flexural strength than the control-GIC 24 hours after mixing into cements, whereas the compressive strength values of the A200and A100f-GICs were the same as the control-GIC. Moreover, HAp increased the flexural strength of GIC and helped maintain its compressive strength, even though HAp particle has very poor compressive strength (approximately 1.0 MPa, which is $1 / 180$ that of Fuji IX glass core particle, $182.8 \mathrm{MPa}$ ). The demonstrated dramatically improved mechanical strength of A100f-GIC, and its facile reaction with GIC, is likely due to the specific properties of HAp100f particles: $10 \mu \mathrm{m}$ particle size, high specific surface area, porous surface, lower crystallinity compared to the other HAps, and mechano-chemical effects. It has been reported that the strength of cement is influenced by the size of the particles and the $\mathrm{P} / \mathrm{L}$, leading to the recommendation that particles should not be too fine or too large in order to achieve high strength ${ }^{35)}$. The flexural strength of A200-GIC is inferior to that of A100f-GIC, even though the particle size of HAp200 is similar to that of HAp100f. It is possible that the reaction of HAp200 with the GIC components occurs more slowly compared to HAp100f, due to the extremely high crystallinity, low specific surface area, and low porosity of HAp200. Moreover, the flexural and compressive strength values of the NanoA-GIC were lower than the A100f-GIC, although the particle size of NanoHAp is smaller than that of HAp100f. The decreased effects of NanoHAp may be due to the same factors as for HAp200: higher crystallinity and lower specific surface area than HAp100f. The remarkable decrease in the compressive strength of A100-GIC may be due to fracturing of the HAp100, since its particle size was too large to improve the mechanical properties of GIC.

HAp particles were not visualized by SEM observations of the fracture surfaces of the HAps-added GICs, except for the A100-GIC, indicating that the cracks in the matrix are caused by the strongly bonded interface between the HAp and the matrix. Moreover, increased fracturing of the GIC core and decreased glass particlematrix-debonding surface was seen in the HAps-added GICs compared to the control-GIC. These results indicate that the GIC matrix is strengthened by adding HAp. SEM observation of both HAp100 particles and A100-GIC fractured surface showed that the GIC matrix components penetrate the countless pores throughout HAp100 (Fig. 5B-1, B-2), showing that HAp adsorbs the matrix during the cement hardening reaction.

In the present study, EDS analyses and SEM observations indicated that HAp adsorbed to GIC matrix containing $\mathrm{Al}, \mathrm{Sr}, \mathrm{F}$, and $\mathrm{Si}$ ions. EDS analyses demonstrated the presence of $\mathrm{Si}$ in the matrix and, to a 
lesser extent, in HAp. Ca could be detected in the matrix phases of the HAps-added GICs by EDS and XPS analyses. The reaction mechanism between HAp and GIC is likely similar to the reaction mechanism between tooth and GIC. Matrices of the A100f-GIC contain more Ca than matrices of the A100- and A200-GICs (Fig. 6). Our results show that HAp100f particles react more easily with polyacrylic acid than HAp100 and HAp200 particles, and that the improved characteristics of HAp100f may be due to a mechano-chemical effect.

GICs can help prevent dental caries by releasing fluoride ions. Approximately $200-300 \mu \mathrm{g} / \mathrm{cm}^{2}$ a month of fluoride ion are needed to prevent enamel demineralization $^{36)}$. In the present study, the accumulated amounts of fluoride during the first 14 days from the A100- and A100f-GICs were 161.1 and $218.3 \mu \mathrm{g} /$ $\mathrm{cm}^{2}$, respectively, whereas that of the control-GIC was $97.6 \mu \mathrm{g} / \mathrm{cm}^{2}$. Thus, the quantity of fluoride released by A100- and A100f-GICs is sufficient for the prevention of enamel demineralization even without fluoride recharge if they are maintained in the oral cavity for one month.

In this study, fluoride ion release and recharge doses of all HAps-added GICs were higher than the control-GIC. Fluoride was included only in the GIC glass powder, so more fluoride ion was released from the HAps-added GICs than from the control-GIC despite the lower fluoride content in the HAps-added GICs. In particular, the fluoride release and recharge behavior of the A100f-GIC was superior to the other HAps-added GICs, indicating that fluoride ion release is improved by adding highly reactive HAp particle.

It has been reported that the fluoride released from GIC is mainly from the matrix ${ }^{37)}$. In addition, Meryon and Smith $^{38)}$ concluded that fluoride released from GIC is not from the GIC core but rather from the matrix. In our study, XPS analysis showed that fluorine contents in the matrices of the A100- and A100f-GICs were higher than in the matrix of the A200-GIC, and that the fluorine content of the A200-GIC was lower than that of the control-GIC. However, the amounts of fluoride ion released from all the HAps-added GICs were significantly higher than from the control-GIC. Moreover, the amount of fluoride ion released from the A200-GIC was similar to that from the A100-GIC over a 14-day period, but the amount of fluoride ion released after recharging the A200-GIC with fluoride ion was higher than for the A100-GIC. These results indicate a discrepancy between the fluoride release dose from HAp-added GIC and the fluoride content in the matrix phase.

Stamboulis ${ }^{39)}$ reported XPS analyses showing the presence of Al-F-Sr(n) and Al-F-Na(n) in Fuji IX-powder. Our study also shows that F1s peaks originate both from organic fluoride $(689.0 \mathrm{eV})$ and metallic fluoride $(686.0$ $\mathrm{eV})$, suggesting that fluoride will react with $\mathrm{Al}$ or $\mathrm{Sr}$ in the glass core. Furthermore, Jones ${ }^{26)}$ reported that fluoride ion uptake of GIC based on calcium alminosilicate glass correlated with the formation of a surface layer rich in $\mathrm{Ca}$ and fluoride, and possibly containing $\mathrm{CaF}_{2}$. In our study, XPS detected Ca from added HAp in the matrix of four HAps-added GICs. The HAps-added GICs released and recharged more fluoride ions than the control-GIC, and so it is possible that $\mathrm{Ca}$ in the HAp influenced the release of fluoride. Therefore, HAp, GIC glass core, and GIC matrix may react with each other. These findings suggest that the release and recharge of fluoride ion occurs in both the matrix and HAps-added GICs.

\section{CONCLUSIONS}

The results from this study demonstrate that the addition of HAp particles with different characteristics may enhance the flexural strength and fluoride ion release properties of conventional restorative GIC. In addition, a novel "apatite glass ionomer cement" with high performance and strength was developed by adding highly reactive HAp particles about $10 \mu \mathrm{m}$ in diameter to conventional restorative GIC. Our results further indicate that HAp functions as an adsorbent and an ion exchangeable agent, rather than as reinforcement, resulting in improved mechanical and chemical properties of GIC.

The mechanisms underlying these improved properties are thought to be:

1) The matrix of HAp-added GIC was strengthened compared to conventional GIC by increased metal ions participating in the cement hardening reaction. The metal ions $\left(\mathrm{Ca}^{2+}\right)$ are supplied by the dissolution of HAp particles.

2) The HAp particles in GIC was reinforced first by the adsorption of GIC matrix and then by the formation of an "intermediate layer" between the surface of the primary HAp crystals and the absorbed matrix.

3) HAp-added GIC was reinforced by adhesion of the improved matrix and the improved HAp particles.

\section{ACKNOWLEDGMENTS}

This research was supported by the Japan Science and Technology Agency (JST) and Japan Society for the Promotion of Science (JSPS) Grant-in-Aid for Scientific Research (A) \#20241020.

The authors would like to thank Mr. Katsuhito Kato, Research \& Development Dept., GC Corporation, Tokyo, Japan, for EDS analyses and helpful discussions, and Mr. Yosuke Umezaki, Department of Chemical Science and Technology, The University of Tokushima, for his technical support in the XRD, TEM, and SAED analyses.

\section{REFERENCES}

1) Wilson $\mathrm{AD}$, Kent BE. The glassionomer cement. A new translucent dental filling material. J Appl Chem Biotechnol 1971; 21: 313.

2) Olivia A, Della Ragione F, Salerno A. Biocompatibility studies on glass ionomer cements by primary cultures of human osteoblasts. Biomaterials 2000; 17: 1351-1356.

3) Burke F, Lynch E. Glass polyalkenoate bond strength to dentine after chemomechanical caries removal. J Dent 1994; 22: 283-291. 
4) Hötz P, McLean JW, Sced I, Wilson AD. The bonding of glass ionomer cements to metal and tooth substrates. Br Dent $\mathrm{J}$ 1977; 142: 41-47.

5) Tam LE, Chan GPL, Yim D. In vivo caries inhibition effects by conventional and resin-modified glass-ionomer restorations. Oper Dent 1997; 22: 4-14.

6) Tyas MJ, Mount GJ, Anusavice KJ, Frencken JE. Minimal intervention dentistry -A review, FDI Commission Project 1-97. Int Dent J 2000; 50: 1-12.

7) Zanata RL, Navarro MF, Barbosa SH, Lauris JR, Franco EB. Clinical evaluation of three materials applied in a minimal intervention caries treatment approach. J Public Health Dent 2003; 63: 221-226.

8) Frencken JE, Pilot T, Songpaisan Y, Phantumvanit P. Atraumatic restorative treatment (ART): Rationale, technique, and development. J Public Health Dent 1996; 56 : 135-140.

9) Frencken JE, Taifour D, van't Hof MA. Survival of ART and amalgam restorations in permanent tooth of children after 6.3 years. J Dent Res 2006; 85: 622-626.

10) Mount GJ. Glass ionomers: a review of their current status. Oper Dent 1999; 24: 115-124.

11) Wilson AD, McLean JW. Glass Ionomer Cement. Illinois: Quintessence Publishing; 1998. p.33-56.

12) Irie M, Nakai H. Mechanical properties of silver-added glass ionomers and their bond strength to human tooth. Dent Mater J 1988; 7: 87-93.

13) Mitra SB. Adhesion to dentin and physical properties of light-cured glass-ionomer liner/base. J Dent Res 1991; 70: 72-74.

14) $\mathrm{Xu} X$, Burgess JO. Compressive strength, fluoride release and recharge of fluoride-releasing materials. Biomaterials 2003; 24: 2451-2461.

15) Costa CA, Hebling J, Garcia GF, Hanks CT. In vitro cytotoxicity of five glass-ionomer cements. Biomaterials 2003; 24: 3853-3858.

16) Souza PPC, Aranha AMF, Hebling J, Giro EMA, Costa CA. In vitro cytotoxicity and in vivo biocompatibility of contemporary resin-modified glass-ionomer cements. Dent Mater 2006; 22: 838-844.

17) Kobayashi M, Kon M, Miyai K, Asaoka K. Strengthening of glass-ionomer cement by compounding short fibers with $\mathrm{CaO}$ $\mathrm{P}_{2} \mathrm{O}_{5}-\mathrm{SiO}_{2}-\mathrm{Al}_{2} \mathrm{O}_{3}$ glass. Biomaterials 2000; 21: 2051-2058.

18) Arita $K$, Nakajima $H$, Nishino $M$, Okabe T. Effect of reinforcements on mechanical properties of glass ionomer. $\mathrm{J}$ Dent Res 1992; 72 (Special issue): 631.

19) Yamamoto Y. The study on hydroxyapatite-polyacrylic acid composite cement (hydroxyapatite-glassionomer cement). J J Dent Mater 1984; 3: 787-796.

20) Yap AUJ, Pek YS, Kumar RA, Cheang P, Khor KA. Experimental studies on a new bioactive material: HAIonomer cements. Biomaterials 2002; 23: 955-962.

21) Arita K, Okada K. Glass powder for glass ionomer cement. JP Patent No. 354509, 2001.

22) Arita K, Lucas ME, Nishino M. The effect of adding hydroxyapatite on the flexural strength of glass ionomer cement. Dent Mater J 2003; 22: 126-136.

23) Hiramatsu Y, Oka Y, Kiyama H. Rapid determination of the tensile strength of rocks with irregular test pieces. MMIJ 1965; 81: 1024-1030.

24) Brunauer S, Emmet PH, Teller E. Adsorption of gases in multimolecular layers. J Am Chem Soc 1938; 60: 309-319.

25) Patterson A. The Scherrer formula for X-ray particle size determination. Phys Rev 1939; 56: 978-982.

26) Jones FH, Hutton BM, Hadley PC, Eccles AJ, Steele TA, Billington RW, Pearson GJ. Fluoride uptake by glass ionomer cements: a surface analysis approach. Biomaterials 2003; 24: 107-119.

27) Ngo HC, Mount GJ, Peters MC. A study of glass-ionomer cement and its interface with enamel and dentin using a lowtemperature, high-resolution scanning electron microscope technique. Quintessence Int 1997; 28: 63-69.

28) Wilson AD, Prosser HJ, Powis DR. Mechanism of adhesion of polyelectrolyte cements to hydroxyapatite. J Dent Res 1983; 62: 590-592.

29) Wilson AD, McLean JW. Glass Ionomer Cement. Illinois: Quintessence Publishing; 1998. p85-86.

30) Lucas ME, Arita K, Nishino M. Toughness, bonding and fluoride-release properties of hydroxyapatite-added glass ionomer cement. Biomaterials 2003; 24: 3787-3794.

31) Venkataraman KS, Narayanan KS. Energetics of collision between grinding media in ball mills and mechanochemical effects. Powder Technology 1998; 96: 190-201.

32) Ab-Ghani Z, Ngo H, McIntyre J. Effect of remineralization/ demineralization cycles on mineral profiles of Fuji IX Fast in vivo using electron probe microanalysis. Aust Dent J 2007; 52: 276-281.

33) Sced IR, Wilson AD. Poly (carboxylic acid) hardenable compositions. Br Pat Appl 1978; 855A: 2028.

34) Nicholson JW, Hawkins SJ, Smith JE. The incorporation of hydroxyapatite into glass-polyalkenoate ("glass-ionomer") cements: a preliminary study. J Mater Sci Mater Med 1993; 4: 418-421.

35) Suwa Y. Development of Bioceramics as medical filling or prosthetic material. New Ceramics 1994; 10: 11-17.

36) Dijkman G, Vries D, Lodding A, Arens J. Long term fluoride release of visible light-activated composites in vitro: a correlation with in situ demineralization data. Caries Res 1993; 27: 117-123.

37) Matsuya S, Matsuya Y, Yamamoto Y, Yamane M. Erosion process of glass ionomer cement in organic acids. Dent Mater J 1984; 3: 210-219.

38) Meryon SD, Smith AJ. A comparison of fluoride release from three glass ionomer cements and a polycarboxylate cement. Int Endod J 1984; 17: 16-24.

39) Stamboulis A, Law RV, Hill RG. Characterisation of commercial ionomer glasses using magic angle nuclear magnetic resonance (MAS-NMR). Biomaterials 2004; 25: 3907-3913. 